\title{
Ichthyosis Bullosa of Siemens
}

National Cancer Institute

\section{Source}

National Cancer Institute. Ichthyosis Bullosa of Siemens. NCI Thesaurus. Code C84777.

A rare autosomal dominant inherited form of ichthyosis. It is characterized by the presence of an erythematous skin with blisters at birth. The skin subsequently becomes dry, flaky and hyperkeratotic. 